\title{
Representation of Trauma in Balachandra Rajan's The Dark Dancer
}

\author{
Narendra Bahadur Chhetri*
}

\begin{abstract}
The research work deals with the theme of Trauma as represented in Balachandra Rajan's partition novel The Dark Dancer (1958). Trauma occurs due to fragmented social structures and unstable psyche. The paper first defines trauma as a theory and attempts at analyzing the novel from the perspective of trauma theory. The researcher will discuss the cause of trauma that the protagonist suffers and its effect upon him. The paper will, in addition, discuss as to why the protagonist suffers split-personality. Finally the researcher also intends to make an assessment if the author has been successful to represent trauma in the novel.
\end{abstract}

Key Words: Trauma, Partition history, bicultural-conflict, split-psyche.

\section{Introduction}

"The Dark Dancer" (1958), a partition novel, noteworthy for its multiple themes, represents the consequences of the partition of India and Pakistan on the people through its fictional characters like V.S. Krishnan, Kamala, Cynthia, Truger, Vijayaraghavan, parents of Kamala and Krishnan, Pratap Singh, and so on. The novel represents the history from the lens of partition trauma and see how it affects the individual. Basically, the novel focuses on the activities of V.S. Krishnan, Kamala and Cynthia to show the effect of partition in India. More precisely this paper analyzes the role of partition in creating trauma among the people with the theoretical support of Larry Ray, Jeffrey Alexander, Dominick LaCapra, and Cathy Caruth. The paper will not only explore the issue of partition between India and Pakistan and its consequences, but also analyze the novel from the prespective of trauma theories propounded by the aforementioned theorists. It will make an analysis as to whether the author has been successful in representing trauma history.
The paper will try to answer such questions as why the protagonist, Krishnan, suffers split-personality, if his split personality is the result of trauma he suffers or the bicultural conflict he experiences.

The researcher will use Balachandra Rajan's The Dark Dancer as primary text, and relevant references, articles, critical reviews and analyses from different sources, i.e. the internet, library etc as secondary sources. As this is a library research, the researcher will rely on books, journals, and other references from library and the internet.

\section{The Dark Dancer}

The Dark Dancer (1958) was written by Balachandra Rajan (1920-2009) who was an Indian diplomat and a scholar of poetry. He "was Fellow of Trinity College Cambridge from 1944 to 1948 but left England to return to his native country, India" (Balachandra Rajan, Life and Career, Para.1). This is a semi-autobiographical novel. Krishnan, the major character, is the mouthpiece of the author. There are similarities between them. For examples, like Krishnan, the writer had studied abroad. He had completed his study in Cambridge.

*Lecturer, Department of English, Butwal Multiple Campus, Butwal, narendrachhetri9@gmail.com 
He was in Delhi when the country was divided. He had seen the partition himself. Like the author, Krishnan, the protagonist, is a Hindu from the south in India. Thus Krishnan is a representative character for the traumatic voice of the author.

When the country was struggling to get freedom, Krishnan also struggled to find freedom in the traditional Hindu family. The novel tells the story of a Brahmin boy, V.S. Krishnan, who returns to India, his native land, after studying for 10 years in England. Upon returning to his country, he finds that his country is in conflict due to partition. Just as the country is trying hard to get freedom, he is also struggling to find "a definition of his life" (Kirkus). He takes up a government job and settles into a family life as his marriage had already been determined with Kamala, another important character in the novel. Kamala, the symbol of non-violence, known as a female Gandhi, is the perfect Hindu wife. Krirshnan had had an affair back in England with Cynthia, an English girl. But their friendship comes to an end after he undergoes an insulting experience while visiting a Hindu temple with Cynthia. He sides with Kamala after he makes a realization that his religion is not too open to him. Then he joins Kamala in her humanitarian acts in parts of India helping Muslims and cholera victims. His wife, Kamala, gets killed while trying to protect a Muslim girl. After her funeral ritual according to Hindu traditions, he joins his government job. The insulting experience that he experienced at the Hindu temple back in the past brings a great change in him. This is the event in his life that makes him decide to perform his wife's, Kamala's, burial as per Hindu rituals. The personal tragedy of Krishnan and the national tragedy of partition run parallel side-by-side together in the novel.

\section{The Dark Dancer: As a Trauma Representation}

Trauma is a psychological injury caused by physical or mental tortures. Cathy Caruth defines trauma as ' an overwhelming experience of some sudden events but the subject's response is delayed' (p. 181). In the light of the definition, Krishnan's overwhelming experience of the events leads to trauma.
In the novel we come across the first scene of violence when Krishnan, Kamala and Vijayaghvan participate in a demonstration against British rule in front of the temporary platform. During the non-violent protest, when Vijayaraghvan is brutally hit by the lathi of the police, Krishnan becomes furious and "picked up the lathi and waved it over his head" (Rajan, p. 40). Then he shouted to the policeman "Come and get it" (Rajan, p. 40). He mocks the police and clashes with them. As a result, he is counterattacked and falls on the ground unconsciously, severely injured leading to hospitalization. We can see the consequences of the traumatic incident in the psyche of Krishnan throughout the novel. His father says "Once you have recovered from your injuries and from the mental aberrations of which they were the result, there is no reason why you cannot return to a normal, reasonable and constructive life" (Rajan, p. 44). Howerve the effect of the injury remains in his psyche. The changes in him due to the sudden catastrophic incident are obvious. He had wanted to become a teacher, but he ends up becoming a civil servant on the instruction of his father. He seems to lose his desire and is seen as an unstable and aloof person.

During the partition, Sikhs and Hindus were on one side and Muslims were on the other side. Due to the conflict, the minority Muslims migrated to Pakistan, a newly formed geography, and Hindus and Sikhs migrated to Hindustan. The majority group raped and killed the minority group calling them as faceless enemy. The trains came carrying thousands of corpses. This is what we see in the novel The Dark Dancer. When Krishnan travels to Shantihpur by train to get united with his wife, Kamala, whom he had betrayed for his extramarital affair with Cynthia, his former classmate in England who came to study about India, there are several confrontations taking place. He meets a Muslim who is travelling in disguised Hindu costume to remain safe.

During their conversation, Krishnan continuously argues that all religions have similar principles and that they advocate for humanism. But the man suddenly becomes violent and puts his knife 
in Krishnan's throat disclosing his true identity. When the Muslim is moved by the good words of Krishnan, he tells his story, "There were six of you against myself and my wife. You did the only thing you know how to do with a woman, and when you'd done enough of it, you killed her... I was there... I ran away. I wasn't able to stand it" (Rajan, p. 196). It is evident that the man wasn't bad from the beginning, rather it was the situation that made him go aggressive against Krishnan.

Losing his wife and son in front of his eyes made him melancholic and traumatized. Larry Ray in her essay "Mourning, Melancholia and Violence" talks of melancholia which she defines as a memory work where "the loss is continually revisited" (p.120). Melancholia as a response to trauma is living with past. Trauma victim remains pessimistic and he is haunted by the past trauma. In melancholia," (the victim) remembers to attack, to counter, to challenge the past loss. "This situation create(s) a more or less unconscious desire to remain within trauma" (LaCapra, p.56). The Muslim man in the novel brings his past, for the time being, out of memory. He can't forget the past event.

The partition trauma narrated in the novel isn't an individual trauma, rather a cultural trauma. Jeffrey Alexander puts it as

Cultural trauma occurs when members of a collectivity feel that they have been subjected to a horrendous event that leaves indelible marks upon their group consciousness marking their memories forever and changing their future identity in fundamental and irrevocable ways (p. 83).

During partition, individual trauma was transferred to cultural trauma. When a member of one religion was attacked by a member from another religion, the whole community became traumatized. The murder of Kamala emerged as a cultural trauma and from it, people learned that killing each other was not right. Hopefully, riots stopped. "...now that the first rush of their anger is over, the shock of how she died may make a difference" (Rajan p. 285). Her death made a difference among the people and they realized that killing each other is not good. Apparently,
Shantihpur became a quieter place. But trauma doesn't disappear so easily from the memory. Somehow it keeps lingering in the memory. Now more than a half century has passed after partition, but still there is the existence of enmity between India and Pakistan. Still a Muslim feels threatened among majority of Hindus and vice-versa. This indicates how trauma roots deep in the memory even after so many years have passed.

Partition of India and Pakistan followed by the deaths of a million people, mass migration, rape and looting separated a husband from his wife, a child from his father, and due to such horrendous genocides, the survivors of the conflict became traumatized for generations. In The Dark Dancer, Kamala is murdered, but the memory of her death envelopes the remaining life of Krishnan. Due to the massacre of their family members in front of their eyes, the Sikh and the Muslim man in the train were wild with vengeance. The same cultural vengeance leads the Hindus of Shantihpur to form a mob for attacking their own hospital even at the cost of spreading of cholera. They could not endure the presence of Muslims in the hospital bed.

Partition of India and Pakistan took place in large scale. Punjab and Bengal were the center for violence. In the novel, violence exceeds as Krishnan travells from New Delhi to Shantihpur. The partition was triumph for Muslims as their dream of a nation materialized. They got independence from India. But for India, it was a loss, a defeat. Both the countries commemorate partition from their own perspective each year on 14th and 15th of August since then.

By constructing the narrative of partition violence, the author offers an opportunity to the people of coming generations to learn a moral from the consequences of such terrific genocide.

Alexander also talks about the process of public memorialization. He says that people can't express traumatic shocks. Rather traumatic experiences are repressed because of social fear. They go through the process of "public memorialization" such as making monuments, museums, memorials, statues, writing literary works to materialize the truth. In memorialization, which also called 'objectification of trauma', people objectify trauma by making monuments 
(by writing works) which helps to minimize the effects of trauma. Thus trauma is neutralized through memorialization in order to restore psychological health of the people in the community. He writes. ".... there is an increasing body of literature that addresses the effects of the repression in terms of the traumas it caused. The aim is to restore collective psychological health by lifting societal repression and restoring memory. To achieve this, social scientists stress the importance of finding through public acts of commemoration-some collective means for undoing repression and allowing the pent-up emotions of loss and mourning to be expressed" (89). Thus Balachandra Rajan writes this novel with a view to neutratlizing the effects of trauma and to restoring psychological health of the people. The novel is seen as a collective means for undoing repression and allowing the pentup emotions of loss and mourning to get expressed.

The novel depicts the conflict of biculturalism. It is about the effects of bicultural conflict. It gives a picture of cultural trauma resulting from bicultural conflict. It is a literary representation of the trauma which both the countries, India and Pakistan, underwent during the partition. The effects of biculturalism have been shown through the protagonist, Krishnan who was born and brought up in southern Hindu family but he was educated in Cambridge University, England. He has spent much of his life in the west. He has a split-personality because he has both Western and Eastern worldviews. In other words, his mind is divided between Western culture and Eastern culture. He is lost between two cultures. He suffers lack of identity. $\mathrm{He}$ is, therefore, like a dark dancer dancing and swinging both ways with no origin of his own. Like the Tandav dance of Lord Shiva for neutralization of his anger, Krishnan also has dark dancer personality for neutralization of his confused mind. The confused mind that he possesses is the result of the conflict of his bicultural background. Cultural confusion, dilemma, misunderstanding make him a dark dancer. He is partially intimate to Kamala and partially inclined to Cynthia. It shows his divided psyche. Trauma accurs due to dislocatedness of identity. He belongs to nowhere - neither to India nor to the UK.
Alexander talks of "claim making" as one of the steps of trauma as a social process. There must be someone to claim threat to identity. Once claimed, it goes to the public. There are some persons who compose collectivities broadcast symbolic representations "of ongoing social events" (Alexander 92-93). Some people make a claim when they experience threat to the collective identity of the members of the community. Alexander notes" (some people) broadcast these representations as members of a social group. These group representations can be seen as claims..." (93). There are two claim-makers in the novel-Kamala and Cynthia. Kamala, the Hindu wife of the protagonist, represents India, Eastern culture. She emphasizes non-violence for freedom. She holds that morality, humanity are important weapons to obtain freedom. She is a symbolic character of a female Gandhi. She leaves Krishnan, her husband, to respect his freedom to be with Cynthia. On the other hand, Cynthia, Krishnan's friend from Cambridge University, represents British India. She claims that he should follow the path of violence to attain freedom. The writer indirectly suggests that Cynthia is responsible to divide Krishnan and Kamala. Cynthia stands for western culture.

Once Krishnan feels humiliated when he is mistreated in a Hindu temple while he was with Cynthia, he begins to explore his origin of identity, then leaves Cynthia and goes to Kamala. His shift from Cynthia to Kamala is the process of identification. He begins to come closer to his native culture, Hinduism. He goes through mourning process, one of the ways of responding to a trauma. In mourning, also called working through, the victim struggles to overcome the past trauma. Krishnan, the protagonist in the novel, works through his traumatic experience and finally decides to follow the path of non-violence. The author in the novel has faild to maintain.

The author in the novel has failed to maintain middle voice technique to represent the trauma of India-Pakistan partition. Maintaining the "middle voice technique" is important while representing trauma history. Hayden White writes 'the middle voice in 
undifferentiated term (is) the proper way of representing the Holocaust" (as quoted in LaCapra 58) which means a writer should follow the middle voice technique to represent trauma. But, Rajan as a writer has failed to maintain middle voice because he celebrates one set of characters over the other. He seems biased in his characterization and presentation of violence. For examples, some Hindu characters such as Kamala, Krishnan, Vijayaraghavan are presented as patriotic, revolutionary and idcal while Muslim, Sikh characters are presented as rapists, blood thirsty, murderous. They are presented negatively. He celebrates/glorifies Kamala and dehumanizes Muslim and Sikh Characters. For example, the writer has picturised the cruelty of the Sikhs to Hindus and Muslims in the lines, "Forget about your sister raped, your mother in the ditches and the haunting face that reminds you of the crime, which is everyone's face, wherever the curved knife slashes" (102). The narrator, here, seems to be afraid of the fear of the Sikh because of the terror they had created in the mind of, the Hindus. Even Ali Jinnah has been made fun of "That Jinnah chap wants a corridor five feet wide and a thousand two hundred miles long, from the Punjab to Bengal. And what's more, he's proposing to line both sides of it with morocco-bound copies of the Koran" (Rajan, p. 106).On the other hand, when Muslim people suffering from cholera hesitate to go to hospital for treatment, Kamala says, 'It isn't different because they are Muslims... They are sick, they're in danger, and our duty is to care for them... it's our responsibility to go out and bring them in" (Rajan, p.226). The writer describes Kamala as "She had always been true to her nature, consistent even in crisis. Looking at her serenity, one could admire its constancy, come to cherish it" (pp. 268-69). A writer shouldn't comment, pass any judgment on characters or events while representing trauma. But, Rajan as a writer has failed to do so.

\section{Conclusion}

To conclude, Rajan's The Dark Dancer represents vivid realities of India-Pakistan partition in 1947, and its effects as a result of ethnic riots between Hindus and Muslims. Krishnan, the protagonist, suffers split-psyche as a result of the event as well as the bicultural conflict he experiences. There were killings, rapes, racial conflicts in India after independence. At the same time, he is lost between two cultures. His psyche is torn apart between Eastern and Western worldviews. He fails to find his identity. Similarly, the novel is the process of memorialization. The author tries to neutralize his traumatic memories as he had witnessed the partition himself. He, therefore, tries to objectify trauma by writing the novel which helps to minimize the effects of trauma. He thereby attempts at restoring psychological health of the people of the country. The novel, no doubt, appeals for humanitarianism. It is only by showing respect to one another that peace can be guaranteed in the world. However, the writer seems biased to characterization as well as representation of trauma history. He has failed to build-up the sense of "Weness". He identifies himself as belonging to one set of characters in the novel. The text should have tried to find a neutral ground to discover the causes of the problem causing the violence. It shouldn't have dehumanized one set of characters to celebrate the other.

\section{References}

Alexender, J. (2012). Trauma: A Social Theory. Cambridge: Polity.

Balachandra Rajan, Life and Career. In Wikipedia Retrieved Jan31, 2020, from https://en. wikipedia.org/wiki/balachandra rajan.

Cathy,C. "Unclaimed Experience: Trauma and the Possibility of History". Course Packet. Literature of War, Conflict and Trauma. M.A. English, $2^{\text {nd }}$ Semester, T.U.

LaCapra, D. (2001). Writing History, Writing Trauma. Baltimore: John Hopkins Up.

Rajan, B. (1958). The Dark Dancer. London: Heinemann.

Ray, L. "Mourning, Melancholia and Violence". Course Packet, Literature of War, Conflict and Trauma. M.A. English, 2nd Semester, T.U.

https://www/kirkusreviews.com,simon and Schuster, June 10 1958. Retrieved Jan31, 2020. 